\title{
AS IDEIAS DOS ALUNOS NAS PESQUISAS DE FORMAÇÃO INICIAL DE PROFESSORES DE CIÊNCIAS
}

\author{
Students' ideas on research \\ into preservice science teacher education programs
}

\author{
João Batista Siqueira Harres ${ }^{1}$. Michelle Camara Pizzato ${ }^{2}$ Ana \\ Paula Sebastiany ${ }^{3}$. Danielle Cenci ${ }^{4}$. Giane Eidelwein ${ }^{5}$. Ivan \\ Francisco Diehl ${ }^{6}$. Marlete Mörs ${ }^{7}$
}

\begin{abstract}
Resumo: Considerando as ideias dos alunos componente importante na formação de futuros professores, apresenta-se uma revisão de pesquisas que implementaram estratégias curriculares inovadoras para promoção da evolução do conhecimento profissional. A análise centrou-se na consideração da existência e do uso didático das ideias dos alunos em 18 artigos publicados, entre 1995 e 2005, nas principais revistas internacionais (em língua inglesa) da área. São apresentadas as características destas pesquisas em termos da metodologia, contexto e perspectiva teórico-prática das abordagens curriculares formativas implementadas. O desenvolvimento profissional alcançado pelos futuros docentes envolvidos foi comparado para identificação de obstáculos e avanços nesse processo. Questões de ordem epistemológica e de coerência entre a intervenção formativa e o modelo didático tomado como referência, pelos pesquisadores/formadores, para avaliar o desenvolvimento profissional inicial destes docentes são elencadas na tentativa de se entender por que, de modo geral, a mudança alcançada é pequena.

Palavras-chave: Formação de professores. Pesquisa. Conhecimento. Ensino de ciências. Ideias.
\end{abstract}

\begin{abstract}
Considering students' ideas as an important component in pre-service teacher education, we conducted a review of research that implemented curriculum advanced strategies to promote the evolution of professional knowledge. Our analysis has focused particularly on accounts of the existence and didactic use of students' ideas in 18 articles published between 1995 and 2005 in major international journals (English) in the area. The characteristics of these researches in terms of methodology, context and theoretical-practice perspective of implemented formative curriculum approaches are presented. The professional evolution of pre-service teachers was compared to determine the obstacles and progress points within this process. Finally, issues of epistemological order and of coherence were determined to assess the initial professional development of these pre-service teachers. The framework of the formative intervention and the didactic models allows issues to be listed in trying to understand why, in general, the change is small.
\end{abstract}

Keywords: Teacher training. Research. Professional. Science education. Ideas.

\footnotetext{
${ }^{1}$ Faculdade de Física, Pontifícia Universidade Católica do Rio Grande do Sul (PUCRS). Prédio 10. Av. Ipiranga, 6681.Partenon, Porto Alegre, RS, Brasil. 90.619-900. joao.harres@pucrs.br

${ }^{2}$ Instituto Federal de Educação, Ciência e Tecnologia do Rio Grande do Sul. Porto Alegre, RS, Brasil.

${ }^{3}$ Pós-Graduanda em Educação em Ciências: Química da Vida e Saúde, UFRGS. Porto Alegre, RS, Brasil.

${ }^{4}$ Pós-Graduanda em Educação, UFRGS. Porto Alegre, RS, Brasil.

5,7 Bolsistas de Iniciação Científica, Centro Universitário UNIVATES. Lajeado, RS, Brasil.

${ }^{6}$ Discente, Instituto Federal de Educação, Ciência e Tecnologia do Rio Grande do Sul. Porto Alegre, RS, Brasil.
} 


\section{Introdução}

A formação de professores vem se constituindo em uma área de pesquisa altamente relevante, na medida em que é o professor, ao fim e ao cabo, quem irá implementar, em sala de aula, os avanços que a pesquisa no ensino e na aprendizagem consolidam.

Este movimento parece ainda mais forte na área de ensino de ciências, provavelmente como resultado justamente do avanço da pesquisa em ensino e aprendizagem nesta área. De modo geral, trabalhos práticos e discussões teóricas sobre aprendizagem significativa, análise do discurso, mudança conceitual, modelos mentais, conhecimento pedagógico do conteúdo, implicações epistemológicas e outros tantos campos de investigação são frequentes na área de ensino de ciências e matemática.

Esse trabalho se insere na perspectiva mais ampla de apontar o valor da pesquisa na área de ensino e aprendizagem para o desenvolvimento profissional de professores de ciências e matemática. A ideia é a de contribuir para os que os avanços da pesquisa no ensino e aprendizagem de ciências dos alunos tenham maior repercussão na formação dos professores e nas pesquisas associadas a esses processos.

Mais especificamente, nossa atenção se volta para a formação inicial de professores por duas razões. A primeira é que, como pesquisadores que formam professores, por um lado, nos parece imprescindível que analisemos os resultados desse processo; e, por outro lado, que aproveitemos o campo de intervenção de que dispomos para justamente investigarmos a transferência dos avanços na pesquisa na área para o âmbito de construção do conhecimento profissional dos futuros professores. Hashweh (1996) afirma que a análise do grau de evolução identificado em diferentes contextos formativos constitui uma linha de investigação crucial para que avancemos como formadores no desenvolvimento em estratégias mais adequadas de desenvolvimento profissional.

A segunda razão tem a ver com os resultados na pesquisa com professores em exercício. Nesse particular, parece haver já um consenso de que as vivências acadêmicas anteriores dos professores (seja na universidade ou, mesmo, na escola) são altamente estruturantes da forma como sua docência se manifesta em sala de aula (KAGAN, 1992; VALCÁRCEL PÉREZ; SÁNCHEZ BLANCO; PRO BUENO, 2005). Assim, consideramos muito importante analisar como são estas vivências e identificar aquelas mais coerentes com uma prática docente desejável baseada nos pressupostos que a área vem apontando como relevantes.

E quais seriam estes pressupostos? Certamente seria difícil encontrarmos uma unanimidade na área. Alguns diriam que estão nas bases epistemológicas do conhecimento trabalhado em sala de aula; outros, na ação direta dos professores; outros apontariam a necessidade de um melhor conhecimento dos processos cognitivos, e outros, ainda, na interação entre estes elementos e no discurso que media esse processo. Todos altamente relevantes, e muitos outros aspectos do complexo processo que é educar professores poderiam ser apontados. Porém, gostaríamos de destacar um que vimos investigando há algum tempo e que, apesar da sua importância, não tem recebido, como mostra esta revisão, a atenção merecida.

Este é o caso da consideração das ideias dos alunos nos processos de formação inicial dos professores. Segundo Treagust e Duit (2008), a pesquisa no ensino de ciências mostrou, nas últimas três décadas, que os estudantes já chegam às aulas de ciências com ideias sobre os fenômenos e conceitos a serem aprendidos, as quais, em geral, não coincidem com as visões 
científicas. Em outras palavras, podemos conceber que já existe um consenso de que os estudantes não podem ser considerados uma tabula rasa. Conforme Von Glaserfeld (1993), o conhecimento é o resultado de uma ação construtiva, e não pode simplesmente ser "transferido" a um receptor. Cada aprendiz deve desenvolvê-lo. Assim, cada novo conhecimento ou procedimento envolve uma interação ativa entre as construções prévias do indivíduo e a nova informação que emerge das situações vividas.

Essas construções têm recebido, na literatura, várias denominações: concepções errôneas, concepções alternativas, concepções intuitivas, conhecimento prévio, teorias implícitas, modelos mentais etc. (TREAGUST; DUIT, 2008). Esta variedade é fruto, muitas vezes, das diferentes perspectivas teóricas que a embasam e dos diferentes momentos históricos da evolução na pesquisa na área. Nesse trabalho nos restringiremos ao uso da expressão ideias dos alunos porque, por um lado, parece ser uma expressão que carrega, implicitamente, uma perspectiva mais relativista do seu status epistemológico; e, por outro lado, porque estamos mais interessados em investigar a forma como os professores lidam com as implicações didáticas da existência dessas ideias.

Além disso, a pesquisa nas ideias dos alunos traz duas implicações importantes para a formação de professores. A primeira é a de que o estudo, as características, as formas de acessar, de analisar e de promover evolução das ideias dos alunos devem fazer parte do conhecimento profissional dos professores (MORRINSON; LERDERMAN, 2003). A segunda é a de que, como esse processo construtivo não se manifesta apenas na aprendizagem de conceitos científicos, mas está presente em qualquer aprendizagem, inclusive a profissional, qualquer processo formativo de professores deve também considerar as ideias dos professores (TARDIF, 2002) - no caso aqui analisado estas seriam as ideias dos professores sobre as ideias dos alunos.

Kagan (1992) afirma que vários estudos empíricos demonstraram que as crenças dos professores são estáveis e resistentes à mudança. Além disso, elas refletem o tipo de aula que vivenciaram como estudantes. Segundo a autora, sabemos pouco sobre como evoluem estas crenças ao longo da carreira de um professor. O que sabemos é que as crenças dos professores principiantes acabam atuando como filtro por meio dos quais são interpretados outros comportamentos de ensino. Em geral, as informações dos cursos universitários e, inclusive, as observações e experiências em sala de aula são transferidas e absorvidas pela pedagogia própria dos futuros professores. Ao final, a formação inicial acaba por não provocar uma ruptura epistemológica e didática que supere a resistência à mudança e favoreça a construção de um conhecimento profissionalizado e crítico (RIVERO; PORLÁN, 2004).

Assim, as ideias dos alunos são fundamentais para qualquer processo de aprendizagem, seja dos alunos nas aulas de ciências, seja dos futuros professores em suas vivências formativas. E é justamente a coerência desta perspectiva da formação inicial de professores que avaliamos nos artigos revisados. Em outras palavras, analisamos se as ideias dos professores sobre as ideias dos alunos são consideradas e trabalhadas a partir delas e com elas na formação inicial. Esta análise foi feita com base em uma seleção e revisão de trabalhos para uma linha de pesquisa sobre como evoluem as concepções práticas dos futuros professores em contextos formativos inovadores (PORLÁN et al., 2010; PÓRLAN et al., 2011). 


\section{Metodologia}

Para esta revisão, escolhemos, nas principais revistas internacionais de educação em ciências no período 1995 a 2005, 18 trabalhos que investigaram alguma estratégia de intervenção curricular inovadora e coerente com a concepção de aprendizagem (neste caso, profissional) mencionada acima. Foram analisados artigos das seguintes revistas: International Journal of Science Education (seis), Journal of Science Teacher Education (cinco), Journal of Research in Science Teaching (quatro) e Science Education (três). Nestes trabalhos fizemos uma análise sobre como foram abordadas as ideias dos alunos durante o processo formativo e, também, sobre como as ideias dos professores (sobre as ideias dos alunos) foram consideradas.

O Quadro 1 resume as características destacadas de cada um dos artigos analisados: o período (em meses ou na unidade de tempo indicada) de intervenção curricular teórica (correspondente ao trabalho na universidade) e de intervenção prática (quando havia, desenvolvida diretamente com alunos em escolas); número de sujeitos investigados; área e nível de preparação dos futuros professores; país de origem; metodologia e técnica de análise das concepções e práticas dos futuros professores.

Por esse quadro, verifica-se que a grande maioria das pesquisas analisadas adotou métodos e técnicas de cunho etnográfico. À exceção de um trabalho desenvolvido na China, o contexto predominante era anglo-saxão, embora várias escolas em que os futuros professores implementavam suas práticas envolviam alunos de diferentes etnias e classes sociais.

Doze trabalhos foram desenvolvidos unicamente com futuros professores de crianças cuja idade corresponde ao nível que, no Brasil, identificamos como as séries iniciais do Ensino Fundamental. Três envolveriam a formação para atuar com crianças das séries finais do Ensino Fundamental. Nas demais, à exceção de uma, não ficou claro se envolveriam ou não, também, idades correspondentes ao nosso Ensino Médio.

A área predominante de formação investigada foi a de Ciências (13 pesquisas). Os outros se distribuíam, em alguns casos simultaneamente, na formação para as áreas de Matemática e Biologia.

Em função dos objetivos que vimos perseguindo na formação de futuros professores, definimos as seguintes categorias de análise dos artigos revisados:

Categoria 1 - Ideias dos Alunos. Nesta categoria analisamos se as ideias dos alunos, como conteúdo da formação profissional dos futuros professores, eram consideradas na intervenção formativa. Em caso positivo, verificou-se se elas eram utilizadas apenas como elemento motivacional ou como elemento cognitivo.

Categoria 2 - As ideias dos professores na abordagem curricular. Aqui analisamos como as ideias dos professores eram consideradas nas diferentes abordagens curriculares das intervenções formativas. À exceção de um artigo, no qual não foi possível identificar o tipo de abordagem, pode-se concluir que, em todos os demais, as ideias dos professores são consideradas.

A classificação das propostas seguiu, por um lado, as denominações apresentadas pelos próprios autores: "fundamentalista (baseada na reforma)", "perspectiva contextualizada", "reflexivo", "investigativo" e "construtivista". Por outro lado, para diferenciar as propostas que se autodenominaram como construtivistas, adaptamos a classificação de García (1999). Nesta classificação, uma perspectiva "construtivista simplista" considera que os futuros professores apresentam ideias (sobre ensino e aprendizagem) antes da intervenção curricular, mas estas ideias são vistas como um 
As ideias dos alunos nas pesquisas ...

Quadro 1. Características e contextos das pesquisas revisadas

\begin{tabular}{|c|c|c|c|c|c|c|c|c|}
\hline $\mathrm{N}^{\circ}$ & $\begin{array}{c}\text { Teoria } \\
\text { (meses) }\end{array}$ & $\begin{array}{l}\text { Prática } \\
\text { (meses) }\end{array}$ & Sujeitos & Área $^{1}$ & Nível $^{2}$ & País & Metodologia & Técnica \\
\hline 1 & 8 & 4 meses & 8 & $\mathrm{C}$ & SF & Canadá & Qualitativa & Entrevistas \\
\hline 2 & 2 & 2 meses & 1 & Ce $\mathrm{M}$ & SI & EUA & Qualitativa & $\begin{array}{l}\text { Entrevistas, gravação de aula, } \\
\text { produção escrita, observações }\end{array}$ \\
\hline 3 & 2 & 2 meses & 1 & C & SI & EUA & Qualitativa & $\begin{array}{l}\text { Entrevistas, questionário, } \\
\text { observações, reflexões }\end{array}$ \\
\hline 4 & 6 & $6 \mathrm{~h}$ por semana & 18 & C & SI & EUA & Qualitativa & Entrevista e produção escrita \\
\hline 5 & 2 & 0 & 12 & C & MF & EUA & Mista & Produção escrita \\
\hline 6 & 30 & 0 & 60 & $\mathrm{C}$ & $\mathrm{SI}$ & Suécia & Mista & Entrevistas e questionário \\
\hline 7 & 8 & $\begin{array}{c}3 \text { meses prévia } \\
\text { à teoria }\end{array}$ & $27 \mathrm{Q}$ e $8 \mathrm{E}$ & $\mathrm{C}$ & SI & Canadá & Qualitativa & Questionário e entrevistas \\
\hline 8 & 2 & 1 dia & 11 & C & $\mathrm{SI}$ & EUA & Qualitativa & Entrevistas \\
\hline 9 & 6 & 1 dia & 18 & $\mathrm{C}$ & SF & EUA & Qualitativa & Entrevista e produção escrita \\
\hline 10 & 12 & 12 & 20 & $\mathrm{C}$ e B & $\mathrm{EF}$ & EUA & Qualitativa & Entrevista e produção escrita \\
\hline 11 & 1 & 0 & 121 & C & SI & EUA & Quantitativa & $\begin{array}{l}\text { Entrevistas, questionário, } \\
\text { gravação de aula }\end{array}$ \\
\hline 12 & 4 & $\begin{array}{c}1 \text { aula para } \\
\text { colegas }\end{array}$ & 21 & C & SI & Austrália & Qualitativa & Entrevista e produção escrita \\
\hline 13 & 12 & 0 & $\begin{array}{l}154 \mathrm{Q} \text { e } \\
22 \mathrm{GF}\end{array}$ & C & SI & Austrália & Mista & $\begin{array}{l}\text { Questionário, observação de } \\
\text { aula, cinco Grupos Focais }\end{array}$ \\
\hline 14 & 12 & $\begin{array}{l}1 \text { aula por } \\
\text { semana }\end{array}$ & 30 & C & SF & EUA & Qualitativa & $\begin{array}{l}\text { Entrevista, produção escrita, } \\
\text { gravação de aulas }\end{array}$ \\
\hline 15 & 10 & 2 meses & 16 & B & SF & China & Qualitativa & Questionário e observação \\
\hline 16 & 12 & 3 dias & 2 & C & SI & EUA & Qualitativa & $\begin{array}{l}\text { Entrevistas gravadas, produção } \\
\text { escrita, gravação de aula }\end{array}$ \\
\hline 17 & 2 & 0 & 12 & M & SI & EUA & Qualitativa & Produção escrita \\
\hline 18 & 12 & 0 & 3 & Ce M & $\mathrm{SI}$ & EUA & Qualitativa & $\begin{array}{l}\text { Entrevistas, produção escrita, } \\
\text { gravação de aula }\end{array}$ \\
\hline
\end{tabular}

${ }^{1}$ C - Ciências, M - Matemática, B - Biologia

${ }^{2} \mathrm{SI}$ - Séries Iniciais, SF - Séries Finais, EF - Ens. Fundamental, FM - Ens. Fundamental e Médio.

Fonte: Dados da pesquisa. Próprios autores

"erro" a ser eliminado pela formação. Já na perspectiva "construtivista complexa", as ideias dos futuros professores têm o seu valor epistêmico próprio. Elas não são, a priori, "corretas" ou "erradas", mas apresentam graus e contextos de complexidade, validade e funcionalidade diferentes, mesmo que umas sejam mais potentes e adequadas que outras.

Além disso, quando não era informado ou não era possível identificar, no trabalho, a diferenciação acima, adotamos a classificação de "espontaneísta" ou "investigativa", proposta por Porlán e Rivero (1998) para os modelos teóricos de formação de professores estruturados segundo uma perspectiva evolutiva do desenvolvimento profissional e baseados em diferentes concepções 
Harres, J. B. S. et al.

de aprendizagem: transmissivo, tecnológico, espontaneísta e, ainda, evolucionista construtivista de cunho investigativo.

Segundo estes autores, um modelo de formação espontaneísta estaria próximo de uma posição de independência da intervenção formativa frente à teoria educacional. O conhecimento profissional seria formado apenas pelo conjunto de experiências advindas do contexto escolar, nutrindo-se de si mesmo. Já em um modelo "investigativo", a formação busca a construção, integrando teoria e prática, de alternativas aos problemas mais importantes na realidade escolar, com vistas à ação e formação profissional.

Categoria 3 - Concepscão de aprendizagem implícita no modelo didático de referência. Para caracterizar o modelo didático de referência, isto é, a concepção de aprendizagem implícita no tipo de aula que os pesquisadores desejavam que os futuros professores implementassem.

Para essa análise, utilizamos também os quatro modelos de formação propostos por Porlán e Rivero (1998) para avaliar o modelo didático de referência (explícito ou implícito), como orientadores da prática docente escolar dos futuros professores. Nesta categoria encontramos, além daqueles encontrados na Categoria 3 , modelos próximos à perspectiva transmissiva e à perspectiva tecnológica. Na primeira, há uma primazia do saber disciplinar, inclusive os saberes relacionados com as ciências da educação, e o saber experiencial, neste caso dos alunos, não é considerado. $\mathrm{Na}$ outra, se questiona a transmissão conceitual pura e simples e abordando da forma mais rigorosa a intervenção docente, a qual não se processa por uma mera reprodução acadêmica, mas através de um recurso tecnológico que garanta uma intervenção eficaz.

Categoria 4 - Evolução das concepções e práticas dos futuros professores. A avaliação dessa evolução do desenvolvimento profissional dos futuros professores foi orientada pelas seguintes questões:

- após as vivências formativas inovadoras, os futuros professores passam a propor e desenvolver aulas nas quais as ideias dos alunos são consideradas como ponto de partida?

- a promoção da sua evolução passa a ser um objetivo educacional concreto, transferindo, dessa forma, o centro do processo educacional dos conteúdos disciplinares para a promoção da evolução das ideias dos alunos, a qual busca uma visão mais complexa da realidade? (GARCÍA, 1998).

\section{Análise dos dados}

O Quadro 2 sintetiza a caracterização das pesquisas que fizemos em função das categorias de análise elaboradas. Nesta análise, buscamos identificar: as características comuns dos processos implementados, os resultados alcançados e as barreiras encontradas na evolução dos futuros professores em relação à consideração das ideias dos alunos. Observando a última coluna desse quadro, a primeira constatação a ser destacada pode ser sintetizada pelo título do relevante trabalho de Mellado (2001): “¿Por que a los profesores nos cuesta tanto cambiar nuestras concepciones y modelos didáticos? De fato, segundo a avaliação dos próprios autores e da nossa, considerando os objetivos da pesquisa, as mudanças são, em geral, muito modestas.

Outra constatação é a de que não é possível estabelecer relação entre as características das pesquisas e das intervenções formativas, como, por exemplo, a existência ou não da parte prática implementada ou a sua duração. Embora isso possa ser consequência dos diferentes 
As ideias dos alunos nas pesquisas ...

Quadro 2. Categorias de análise para caracterização das pesquisas

\begin{tabular}{|c|c|c|c|c|}
\hline N & $\begin{array}{c}\text { Categoria 1 } \\
\text { Ideia dos Alunos }\end{array}$ & $\begin{array}{c}\text { Categoria 2 } \\
\text { Abordagem Curricular }\end{array}$ & $\begin{array}{c}\text { Categoria 3 } \\
\text { Modelo Didático }\end{array}$ & $\begin{array}{c}\text { Categoria 4 } \\
\text { Houve mudança? }\end{array}$ \\
\hline 1 & Não identificado & Construtivista complexo & Misto & Pequena \\
\hline 2 & Não existem & Construtivista simplista & Transmissivo & Pequena \\
\hline 3 & Não identificado & Construtivista/ reflexivo & Construtivista simplista & Grande \\
\hline 4 & Não existem & Fundamentalista (baseada na reforma) & Transmissivo & Pequena \\
\hline 5 & Existem & Construtivista simplista & Transmissivo & Pequena \\
\hline 6 & Existem & Construtivista/reflexivo/ investigativo & Transmissivo & Pequena \\
\hline 7 & Existem & Construtivista complexo & Transmissivo & Pequena \\
\hline 8 & Existem & Investigativo & Construtivista complexo & Pequena \\
\hline 9 & Não existem & Espontaneísta & Transmissivo & Pequena \\
\hline 10 & Existem & Construtivista simplista & Construtivista simplista & Pequena \\
\hline 11 & Motivação & Construtivista simplista & Transmissivo & Pequena \\
\hline 12 & Não identificado & Não identificado & Investigativo & Pequena \\
\hline 13 & Existem & Construtivista/reflexivo/investigativo & Construtivista simplista & Grande \\
\hline 14 & Existem & Construtivista simplista & Construtivista simplista & Pequena \\
\hline 15 & Existem & Construtivista simplista & Transmissivo & Pequena \\
\hline 16 & Existem & Construtivista/ reflexivo & Tecnológico & Pequena \\
\hline 17 & Não existem & Construtivista simplista & Investigativo & Pequena \\
\hline 18 & Não existem & Perspectiva contextualizada & Construtivista simplista & Média \\
\hline
\end{tabular}

Fonte: Dados da pesquisa. Próprios autores

critérios com que a mudança dos professores é avaliada. Um único aspecto que chama a atenção é que, entre as pesquisas desenvolvidas no contexto norte-americano, menos da metade (cinco de um total de 12) se encontra no grupo de maior coerência e mudança.

Tentando estabelecer relações a partir dessa síntese, o que se observa é que não há, de modo geral, muita coerência nos processos de aprendizagem profissional analisados. A maioria das abordagens curriculares está apoiada em uma posição próxima ao modelo de mudança conceitual, baseado em Posner et al. (1982), no qual se parte do princípio de que o sujeito aprendiz possui ideias anteriores às vivências formativas. Porém, nem sempre isto se reflete na inclusão das ideias dos alunos como um conteúdo formativo ou na busca de que os futuros professores elaborem propostas didáticas que considerem, partam e promovam evolução das ideias dos alunos. Outras vezes, ocorre o contrário, isto é, se deseja modelos didáticos avançados sem que se promova espaço formativo coerente com isso.

Com exceção de três trabalhos (nº 1, 3 e 12) nos quais não foi possível identificar se as ideias dos alunos eram consideradas ou não e de um que enfatiza as ideias dos alunos apenas como elemento motivacional ( $\left.\mathrm{n}^{\circ} 11\right)$, nove pesquisas $(50 \%$ da amostra) tomam as 
ideias dos alunos como um conteúdo da formação profissional do professor de ciências. Todas estas propõem abordagens curriculares avançadas (construtivista simplista ou complexa, investigativa e reflexiva).

Cinco destes trabalhos, que concebem a aprendizagem profissional como um processo de mudança conceitual análogo à aprendizagem de conceitos científicos na escola $\left(n^{\circ} 5,6,7\right.$, 15 e 16), não avaliam a evolução da prática docente dos futuros professores nesta mesma perspectiva. Isto é, nestes trabalhos uma prática docente é considerada adequada em função da correção com que o conhecimento científico é "transmitido" pelos futuros professores e "aprendido" pelos estudantes em aula. A avaliação do uso das ideias dos alunos em sala de aula, pelos futuros professores, está ausente das análises do avanço promovido pela abordagem curricular implementada. Um destes ( $\left.n^{\circ} 7\right)$ menciona a importância das ideias dos alunos na futura prática docente, mas apenas como algo que, em função do processo formativo vivenciado, os futuros professores estariam mais abertos a considerar quando em efetivo exercício.

Quanto ao tipo de intervenção curricular, encontramos dez trabalhos de cunho construtivista, sendo dois construtivistas complexo, e os demais distribuídos entre reflexivo, investigativo, espontaneísta e contextualizado. Apenas um trabalho ( $\left.n^{\circ} 5\right)$ envolve uma comparação entre grupos submetidos a diferentes abordagens formativas, e apenas seis não envolviam, paralelamente à abordagem teórica, uma imersão prática no contexto escolar.

Analisando como as ideias dos alunos são consideradas e abordadas nesses processos formativos, encontramos que cinco pesquisas não tratam de como os futuros professores devem considerar as ideias dos alunos. Destas, à exceção de uma ( $\left.n^{\circ} 4\right)$, as demais adotam uma abordagem construtivista ou análoga (espontaneísta ou contextualizada) no desenvolvimento das atividades formativas promovidas. Assim, estas pesquisas parecem considerar, implicitamente, que os professores são uma tabula rasa em relação as suas concepções e prática docentes.

Ainda com relação aos nove trabalhos que consideram que os alunos chegam à sala de aula com ideias já construídas, à exceção de um $\left(n^{\circ} 7\right)$, todos se baseavam em propostas formativas e conduziam análises partindo do princípio de que estas ideias são erradas do ponto de vista científico e, portanto, devem ser substituídas. Em outras palavras, na prática, estes trabalhos acabam adotando uma perspectiva epistemológica absolutista, no sentido toulminiano do termo (HARRES; PORLÁN, 1999), na qual as ideias científicas têm um status superior às outras ideias. O que encontramos de comum nestes trabalhos é o pouco avanço identificado pelos próprios autores na implementação, por parte dos futuros professores, de propostas docentes de cunho construtivista.

Apenas dois trabalhos foram classificados como de perspectiva construtivista complexa, isto é, aquela em que as ideias dos alunos não são vistas como um erro a eliminar, mas um conhecimento que tem a sua validade e os seus limites dentro de um determinado contexto, isto é, com seu valor epistêmico próprio (HARRES; ROCHA; HENZ, 2001). Porém entre estes trabalhos encontramos uma concepção de aprendizagem implícita no modelo didático de referência pouco avançado.

Por fim, a incidência maior de futuros professores que passam a considerar as ideias dos alunos de modo mais consistente em suas concepções e práticas, está presente naquelas intervenções formativas mais coerentes em todo o processo. Nestas, parece haver uma vinculação maior entre consideração das ideias dos alunos, a abordagem curricular e a concepção de aprendizagem implícita nos modelos didáticos de referência. 
Este é, segundo nossa avaliação, o caso dos trabalhos no 3,13 e 18. Os sujeitos destas pesquisas passam a ser mais conscientes das suas ideias prévias sobre ensino e aprendizagem e, também, práticas docentes já bem mais próximas de uma perspectiva desejável de referência (frase parece incompleta. Verificar). Entretanto, neles ainda estão presentes posições dualistas, coerentes com um estágio de transição do seu desenvolvimento profissional (HARRES et al., 2005; PORLÁN et al., 2010; PORLÁN et al., 2011).

\section{Conclusões}

Com vistas à construção de uma visão geral sobre o desenvolvimento do conhecimento profissional dos professores, essa revisão esteve centrada na análise de como a formação inicial pode promover a construção de uma concepção de aprendizagem centrada nas ideias dos alunos e da proposição de intervenções didáticas que promovam a sua evolução.

A revisão realizada mostra que, de modo geral, a evolução das concepções e práticas dos futuros professores em direção a uma maior consideração das ideias dos alunos parece ser um processo mais complexo do que somente implementar um currículo formativo inovador, distante ainda de novas perspectivas para o ensino e a aprendizagem (POZO et al., 2006). Como apontam Joram e Gabriele (1998), estes resultados parecem confirmar que os programas formativos devem ser conscientes da dificuldade que implica mudar as concepções dos futuros professores.

As mudanças identificadas em maior ou menor escala parecem não estar relacionadas às variáveis de contexto, nível e/ou área futura de atuação docente. Isto não é de surpreender já que mesmo professores experientes apresentam dificuldades para lidar com as ideias dos alunos (HAND; TREAGUST, 1994; MORRISON; LEDERMAN, 2003). Como mostra o trabalho de Hand e Treagust (1994), professores em exercício têm dificuldade em considerar as ideias dos alunos. Estes autores constataram que $70 \%$ das atividades iniciais de ensino propostas pelos professores investigados estavam centradas neles próprios. Da mesma forma, Hollon, Roth e Anderson (1991) verificaram que mesmo bons professores experientes têm dificuldades em considerar e trabalhar com as ideias dos alunos. A maioria usa estratégias de baixo nível para explicitá-las e, depois, não sabem o que fazer.

De modo geral, pudemos identificar um avanço maior em direção às práticas docentes desejáveis, isto é, em direção a uma perspectiva construtivista complexa da aprendizagem associada a uma metodologia de ensino por investigação (PORLÁN, 1993), naqueles processos nos quais havia uma coerência maior entre a concepção de aprendizagem profissional e a concepção de aprendizagem de referência para o ensino de ciências.

Os dados indicam que esta coerência favorece uma maior consciência, por parte dos futuros professores, sobre as suas ideias prévias sobre ensino e aprendizagem. Ela favorece também uma maior consciência sobre a forma, em geral, fragmentada, com que eles concebem o próprio conhecimento específico, aumentando, assim, a clareza sobre o que se sabe e o que não se sabe.

O maior obstáculo identificado nesses processos, confirmado também por outros trabalhos desenvolvidos principalmente com professores em exercício, parece ser de natureza epistemológica (LEDERMAN, 1992; PORLÁN; RIVERO, 1998; HARRES, 1999; ABD-EL- 
Harres, J. B. S. et al.

KHALICK, 2005). A crença de que a ciência é um corpo objetivo de conhecimentos criados através de um método rígido e rigoroso (WALLACE; KANG, 2004) favorece que muitos futuros professores que passam a considerar as ideias dos alunos apresentem dificuldade para explorar a plausibilidade e a frutibilidade dessas ideias (HEWSON et al., 1999), o que é coerente com uma concepção na qual a ciência não está em questão. De fato, Hashweh (1996), pesquisando com professores em exercício, também encontrou que aqueles que possuíam concepções epistemológicas mais relativistas eram mais sensíveis à existência de concepções alternativas dos estudantes, além de possuírem um repertório maior de estratégias de ensino para promover mudança conceitual.

Finalmente, é muito importante que os programas de formação inicial capacitem os futuros professores para analisarem e considerarem didaticamente as inúmeras investigações sobre as ideias dos alunos e sua importância na aprendizagem na área de ciências (DAVIS; PETISH, 2005). Morrison e Lederman (2003) propõem que os futuros professores deveriam iniciar sua ação docente dispondo de um conhecimento amplo sobre a variedade de préconcepções que eles poderão encontrar na sua área específica, além de uma introdução ao fato de que estas ideias podem diferir das crenças científicas aceitas. Nesse sentido, a obra de Cubero (2000) é um ótimo exemplo.

Como afirmam Porlán et al. (2010, 2011), acreditar que de maneira espontânea os sujeitos em formação possam realizar diferentes integrações epistemológicas entre o mundo consciente da teoria e o mundo imediato e inseguro da ação, é uma das causas do fracasso da formação dos professores e uma das variáveis que favorecem a permanência do modelo hegemônico de ensino.

De fato, o conhecimento profissional dos professores (da mesma forma que o conhecimento dos alunos) está em permanente evolução e não parte de zero, isto é, sempre existe um conhecimento didático prévio. Portanto, os processos de formação inicial devem estar orientados para uma mudança gradativa desse conhecimento, partindo do conhecimento profissional prévio dos futuros professores, pois, somente assim, será possível favorecer que estes, por sua vez, possam também adotar posturas de maior consideração do conhecimento prévio dos seus alunos (HARRES et al., 2005).

Dito de outra forma, como assinala Powell (1996), é necessário ter em conta as cosmovisões pessoais dos futuros professores para favorecer a progressão desde uma epistemologia objetivista - centrada nos conteúdos científicos tradicionais, sem consideração das ideias dos alunos, e na qual a cultura acadêmica é o único referente na hora de acessar e analisar as ideias dos alunos - para uma epistemologia subjetivista, na qual as ideias dos alunos são o centro do currículo, permitindo, pela interação com os novos conhecimentos, um processo realmente construtivo de aprendizagem. 
As ideias dos alunos nas pesquisas ...

\section{Referências}

ABD-EL-KHALICK, F. Developing deeper understandings of nature of science: the impact of a philosophy of science course on preservice science teachers' views and instructional planning. International Journal of Science Education, London, v. 27, n. 1, p. 15-42, 2005.

CUBERO, R. Cómo trabajar con las ideas de los alumnos. Sevilha: Díada, 2000.

DAVIS, E.; PETISH, D. Real-world applications and instructional representations among prospective elementary science teachers. Journal of Science Teacher Education, Dordrecht, v. 16, n. 4, p. 263-286, 2005.

GARCÍA, J. E. A natureza do conhecimento escolar: transição do cotidiano para o científico ou do simples para o complexo? In: RODRIGO, M. J.; ARNAY, J. A. (Org.).

Conhecimento cotidiano, escolar e científico: representação e mudança. São Paulo: Ática, 1998. p. 75-101. (A construção do conhecimento escolar, 1). 1999. Las ideas de los alumnos. Cuadernos de Pedagogía, Barcelona, v. 276, p. 58-64,

HAND, B.; TREAGUST, D. F. Teachers' thoughts about changing to constructivist teaching/learning approaches within junior secondary science classrooms. Journal of Education for Teaching, Oxfordshire, v. 20, n. 1, p. 97-112, 1994.

HARRES, J. B. S. et al. Laboratórios de ensino: inovação curricular na formação de professores de ciências. São Paulo: ESETec Editores Associados, 2005.

HARRES, J. B. S. Uma revisão de pesquisas nas concepções de professores sobre a natureza da ciência e suas implicações para o ensino. Investigações em Ensino de Ciências, Porto Alegre, v. 4, n. 3, p. 197-212. 1999.

HARRES, J. B. S.; PORLÁN ARIZA, R. La epistemología evolucionista de Stephen Toulmin y la enseñanza de las ciencias. Investigación en la Escuela, Sevilla, v. 39, p. 17 26, 1999.

HARRES, J. B. S.; ROCHA, L. B.; HENZ, T. O que pensam os professores sobre o que pensam os alunos. Uma pesquisa em diferentes estágios de formação no caso das concepções sobre a forma da Terra. Revista Brasileira de Pesquisa em Educação em Ciências, Belo Horizonte, v. 1, n. 2, p. 40-50, 2001.

HASHWEH, M. Z. Effects of science teachers' epistemological beliefs in teaching. Journal of Research in Science Teaching, New York, v. 33, n. 1, p. 47-63, 1996.

HEWSON, P. W. et al. Educating prospective teachers of biology: findings, limitations, and recommendations. Science Education, Hoboken, v. 83, n. 3, p. 373-384, 1999.

HOLLON, R. E.; ROTH, K.; ANDERSON, C. W. Science teachers' conceptions of teaching and learning. In: BROPHY, J. (Ed.). Advances in research on teaching. New York, JAI Press, 1991. v. 2. p. 145-185. 
Harres, J. B. S. et al.

JORAM, E.; GABRIELE, A. J. Preservice teachers' prior beliefs: transforming obstacles into opportunities. Teaching and Teacher Education, New York, v. 14, n. 2, p. 175-191, 1998.

KAGAN, D. M. Professional growth among preservice and beginning teachers. Review of Educational Research, Washington, v. 62, n. 2, p. 129-69, 1992.

LEDERMANN, N. G. Students' and teachers' conceptions of the nature of science: a review of the research. Journal of Research in Science Teaching, New York, v. 29, n. 4, p. 331-359, 1992.

MELLADO, V. ¿Por qué a los profesores de ciencias nos cuesta tanto cambiar nuestras concepciones y modelos didácticos? Revista Interuniversitária de Formación del Profesorado, Zaragoza, v. 40, p. 17-30, 2001.

MORRINSON J. A.; LEDERMANN, N. G. Science teachers' diagnosis and understanding of students' preconceptions. Science Education, Hoboken, v. 87, n. 6, p. 849-867, 2003.

PORLÁN, R. Constructivismo y escuela: hacia un modelo de enseñanza-aprendizaje basado en la investigación. Sevilha: Díada. 1993.

PORLÁN, R.; RIVERO, A. El conocimiento dos profesores: en caso del área de las ciencias. Sevilla: Díada, 1998.

PORLÁN, R. et al. El cambio del profesorado de ciencias I: marco teórico y formativo. Enseñanza de las Ciencias, Barcelona, v. 28, n. 1, p. 31-46, 2010.

El cambio del profesorado de ciencias II: itinerarios de progresión y obstáculos en estudiantes de magisterio. Enseñanza de las Ciencias, Barcelona, v. 29, n. 3, p. 353-370, 2011.

POSNER, G. J. et al. Accommodation of a scientific conception: toward a theory of conceptual change. Science Education, Hoboken, v. 66, n. 2, p. 211-27, 1982.

POWELL, R. R. Epistemological antecedents to culturally relevant and constructivist classroom curricula: a longitudinal study of teachers' contrasting world views. Teaching and Teacher Education, New York, v. 12, n. 4, p. 365-384, 1996.

POZO, J. I. et al. Nuevas formas de pensar la enseñanza y el aprendizaje: las concepciones de profesores y alumnos. Barcelona: Graó, 2006.

RIVERO, A.; PORLÁN, R. The difficult relationship between theory and practice in an inservice course for science teachers. International Journal of Science Education, London, v. 26, n. 10, p. 1223-1245, 2004.

TARDIF, M. Saberes docentes e formação profissional. Petrópolis: Vozes, 2002.

TREAGUST, D. F.; DUIT, R. Conceptual change: a discussion of theoretical, methodological and practical challenges for science education. Cultural Studies in Science Education, Dordrecht, v. 3, n. 2, p. 297-328, 2008. 
VALCÁRCEL PÉREZ, M. V.; SÁNCHEZ BLANCO, G.; PRO BUENO, A. de. Viabilidad de las propuestas didácticas planteadas en la formación inicial: opiniones, dificultades y necesidades de profesores principiantes. Enseñanza de las Ciencias, Barcelona, v. 23, n. 3, p. 357-378, 2005.

VON GLASERFELD, E. Questions and answers about radical constructivism. In: TOBIN, K. (Ed.). The practice of constructivism. Washington: American Association for the Advancement of Science Press, 1993. p. 23-38.

WALACE, C. S.; KANG N-H. An investigation of experienced secondary science teachers' beliefs about inquiry: an examination of competing belief sets. Journal of Research in Science Teaching, New York, v. 41, n. 9, p. 936-960, 2004. 
Harres, J. B. S. et al.

\section{Anexo A - Lista de artigos revisados}

1. AGUIRRE, J. M.; HAGGERTY, S. M. Preservice teachers' meanings of learning. International Journal of Science Education, London, v. 17, n. 1, p. 119-131, 1995.

2. BRYAN, L. A. Nestedness of beliefs: examining a prospective elementary teacher's belief system about science teaching and learning. Journal of Research in Science Teaching, New York, v. 40, n. 9, p. 835-868, 2003.

3. BRYAN, L. A.; ABELL, S. K. Development of professional knowledge in learning to teach elementary science. Journal of Research in Science Teaching, New York, v. 36, n. 2, p. 121-139, 1999.

4. DAVIS, E. A.; PETISH, D. Real-world applications and instructional representations among prospective elementary science teachers. Journal of Science Teacher Education, Dordrecht, v. 16, n.4, p. 263-286, 2005.

5. DHINDSA, H. S.; ANDERSON, O. R. Using a conceptual-change approach to help preservice science teachers reorganize their knowledge structures for constructivist teaching. Journal of Science Teacher Education, Dordrecht, v. 15, n.1, p. 63-85, 2004.

6. EKBORG, M. Student-teachers' learning outcomes during science subject matter courses. International Journal of Science Education, London, v. 27, n. 14, p. 1671-1694, 2005.

7. GUSTAFSON, B. J.; ROWELL, P. M. Elementary preservice teachers: constructing conceptions about learning science, teaching science and the nature of science. International Journal of Science Education, London, $v$. 17 , n. 5, p. 589-605, 1995.

8. HAEFNER, L. A.; ZEMBAL-SAUL, C. Learning by doing? Prospective elementary teachers' developing understandings of scientific inquiry and science teaching and learning. International Journal of Science Education, London, v. 26, n. 13, p. 1653-1674, 2004

9. HANCOCK, E. S.; GALLARD, A. J. Preservice science teachers' beliefs about teaching and learning: the influence of K-12 field experiences. Journal of Science Teacher Education, Dordrecht, v. 15, n. 4, p. 281-291, 2004.

10. HEWSON, P. W. et al. Educating prospective teachers of biology: findings, limitations, and recommendations. Science Education, Hoboken, v. 83, n. 3, p. 373-384, 1999.

11. LING L. L.; GABEL, D. L. Effectiveness of a constructivist approach to science instruction for prospective elementary teachers. International Journal of Science Education, London, v. 27, n. 10, p. 1143-1162, 2005.

12. PETERSON, R. F.; TREAGUST, D. F. Learning to teach primary science through problem-based learning. Science Education, Hoboken, v. 82, n. 2, p. 215-237, 1998.

13. WATTERS, J. J.; GINNS, I. S. Developing motivation to teach elementary science: effect of collaborative and authentic learning practices in preservice education. Journal of Science Teacher Education, Dordrecht, v. 11, n. 4, p. 301-321, 2000.

14. YERRICK, R. K.; HOVING, T. J. One foot on the dock and one foot on the boat: differences among preservice science teachers' interpretations of field-based science methods in culturally diverse contexts. Science Education, Hoboken, v. 87, n. 3, p. 390-418, 2003.

15. YIP, D.V. Promoting the development of a conceptual change model of science instruction in prospective secondary biology teachers. International Journal of Science Education, London, v. 23, n. 7, p. 755-770, 2001.

16. ZEMBAL-SAUL, C.; BLUMENFELD, P.; KRAJCIK, J. Influence of guided cycles of planning, teaching, and reflection on prospective elementary teachers' science content representations. Journal of Research in Science Teaching, New York, v. 37, n. 4, p. 318-339, 2000.

17. ZEMBAL-SAUL, C. et al. Web-based portfolios: a vehicle for examining prospective elementary teachers' developing understandings of teaching science. Journal of Science Teacher Education, Dordrecht, v. 13, n. 4, p. 283-302, 2002.

18. ZEMBAL-SAUL, C.; KRAJCIK, J.; BLUMENFELD, P. Elementary student teachers' science content representations. Journal of Research in Science Teaching, New York, v. 39, n. 6, p. 443-463, 2002.

Artigo recebido em 12/06/2011. Aceito em 07/12/2011. 